\title{
Erotomania Coloured by Social Media Usage - A Case Report
}

\author{
Amritha Prasad¹, Pallavi Abhilasha², Sivabalan E³, Thirunavukarasu Manickam \\ 1, 2, 3, 4 Department of Psychiatry, SRM Institute of Science and Technology, Chennai, Tamil Nadu, India.
}

\section{PRESENTATION OF CASE}

A 21-year-old married female Mrs. X, discontinued studies in B.Sc., not employed, with no past family or personal psychiatric history, presented to our OPD claiming that she was in love with a boy from her $12^{\text {th }}$ grade. Mrs. X believes the guy to be a high ranking police officer and was immensely rich and he was the one who was taking care of her. The parents and her close relatives were oblivious to any of these statements or circumstances. The patient kept insisting that her parents got her married to another guy and would constantly make proclamations / threaten them, by claiming that her love would come and marry her. During the course of these delusions, patient even started going frequently to neighbor's house who was a police officer, divorced with two kids. Parents got vexed with her and fixed her marriage and got her married. But on the first day of marriage she told her husband that she is in love with a guy and would chat with him on Facebook. She did not want to get married but was forced into it. Following this the patient left home and came back to her place. The in-laws filed a case against her and the police officer who enquired the case, on suspicion that she could be suffering from mental health problem requested her parents to consult a psychiatrist. When probed, patient revealed that she chats with the guy on Facebook and upon further probing she revealed that she would message many men with similar sounding name. She would even send them inappropriate messages and would be constantly on phone, texting different men.

Patient was admitted in the psychiatry ward for further management and treatment. During ward stay, patient underwent a full laboratory workup consisting of a basic metabolic profile, complete blood count, rapid plasma regain and thyroid panel, all of which showed no significant findings. Urine drug screening was done to rule out substance abuse which turned out to be negative. During interview no mood symptoms as well as no evidence of any disorganized thoughts or disorganized behavior was endorsed.

Even during the ward stay patient would be stuck on phone messaging guys on Facebook. If asked for her mobile phone, she would start to cry and she even tried to attempt suicide by harming herself. She would even show photographs of random men messaging her.

\section{CLINICAL DIAGNOSIS}

Due to the presence of non-bizarre delusions a diagnosis of delusional disorder, erotomanic type was made.

\section{DISCUSSION OF MANAGEMENT}

Second generation antipsychotics are considered as first line of antipsychotics in case of delusional disorders and risperidone was preferred over olanzapine due to its more favorable metabolic profile. Patient was started on T. Risperidone and was titrated to a dosage of $6 \mathrm{mg}$. Patient improved with risperidone and was discharged and was asked for follow up.
Corresponding Author: Dr. Amritha Prasad. A3, Old Medical Staff Quarters, SRM Campus, Potheri, Chennai, Tamil Nadu, India.

E-mail: amrithaprasad09@gmail.com

DOI: $10.14260 / \mathrm{jemds} / 2020 / 764$

How to Cite This Article:

Prasad A, Abhilasha P, Sivabalan E, et al. Erotomania coloured by social media usage - a case report. J Evolution Med Dent Sci 2020;9(46):3495-3496, $10.14260 / \mathrm{jemds} / 2020 / 764$

Submission 15-07-2020,

Peer Review 02-01-2020,

Acceptance 09-10-2020,

Published 16-11-2020.

Copyright (c) 2020 Amritha Prasad et al. This is an open access article distributed under Creative Commons Attribution License [Attribution 4.0 International (CC BY 4.0)] 


\section{DISCUSSION}

The case of Mrs. $\mathrm{X}$ remains unique as the individual has resorted to social media as a means to augment her delusions. This case describes how social media could help a person to get engrossed and fixate on to contact another person. Hirjak and Fuchs drew four main parallels between this schizophrenic self-experience and internet technologies: concealed workings / effects, magical dissolution of boundaries, virtualization of the real world and reification of the psyche. ${ }^{1}$

Social media increases the availability of the virtual world to the patients and enhance the accessibility of stalking measures. This information also needs to be assessed when considering treatment. Quick intervention is required to curb this behaviour from escalating. Social media users should think wisely of how much personal data to be revealed. Further research is needed to know the detailed interplay between social media and erotomanic delusions.

Erotomania is an uncommon disorder, commonly misunderstood, characterized by persistent erotic delusion. Prior to official recognition various authors have described and named this syndrome. Parisian physician Bartholomy Pardoux (1545 - 1611), who discussed the pathology of love in his book, Disease of the Mind, and distinguished between uterine furors (nymphomania) and insane love (erotomania). Sigmund Freud, in 1911, called the illness erotomania, meaning "too much love". G.G. De Clerambault, in $1942^{2}$ classified the symptoms into the disorder he referred to as "Psychose Passionelli." According to De Clerambault he distinguished two different types of erotomania, one is pure or primary erotomania; in which delusion exists alone. In secondary form, the disorder is associated with other psychosis most commonly paranoid schizophrenia.

Erotomania is a delusional disorder of relatively rare condition where an individual believes that another person of higher status is in love with him or her. The prevalence rate of this disorder is around $0.2 \% .^{3}$ There are many theories which explains the aetiology of this delusional disorder. Recent theories have postulated that social media networks play a pivotal role in enmeshing technology into the delusional systems of people who are already predisposed. ${ }^{4}$ This is the Cinderella syndrome, the young girl's fantasy of prince charming. The ubiquitous use of Facebook, Instagram, Snap Chats and other social media is felt by all ${ }^{5}$ Social networks are having a major role in our day to day life wherein online communications can outweigh our personal contacts. Adolescents are seen to be posting detailed personal content with minimal privacy settings. ${ }^{6}$ Easy accessibility of social media networking has led to cyber-crime such as cyber bullying, cyber stalking and cyber harassment. This is a case report of a young female who exhibited cyber stalking behavior motivated by delusions.

Financial or other competing interests: None.

Disclosure forms provided by the authors are available with the full text of this article at jemds.com.

\section{REFERENCES}

[1] Hirjak D, Fuchs T. Delusions of technical alien control: a phenomenological description of three cases. Psychopathology 2010;43(2):96-103.

[2] De Clerambault GG. Les Psychoses Passionelles, in Oeuvere Psychiatrique: Paris: Presses Universities, de France 1942: p. 331, 337-339, 357, 408.

[3] Faden J, Levin J, Mistry R, et al. Delusional disorder, erotomanic type, exacerbated by social media use. Case Rep Psychiatry 2017;2017:8652524.

[4] Krishna N, Fischer BA, Miller M, et al. The role of social media networks in psychotic disorders: a case report. Gen Hosp Psychiatry 2013;35(5):576.e1-2.

[5] Williams AL, Merten MJ. A review of online social networking profiles by adolescents: implications for future research and intervention. Adolescence 2008;43(170):253-74.

[6] Kalbitzer J, Mell T, Bermpohl F, et al. Twitter psychosis: a rare variation or a distinct syndrome? J Nerv Ment Dis 2014;202(8):623. 